\title{
Numerical Study of Failure Modes and Crack Propagation in 2A12 Aluminum Target against Blunt-Nosed Projectile at Low Yaw Angle
}

\author{
Y. F. Deng, ${ }^{1}$ J. F. Li, B. H. Jia, and G. Wei \\ College of Aeronautical Engineering, Civil Aviation University of China, Tianjin, China \\ 1 13512013505@163.com
}

УДК 539.4

\section{Численное моделирование характера разрушения и роста трещин в мишени из алюминиевого сплава $2 A 12$ при ее соударении со снарядом с затупленной носовой частью при малых углах атаки}

\author{
Ю. Ф. Денг, Ж. Ф. Ли, Б. Х. Жиа, Г. Вей \\ Китайский университет гражданской авиации, Тяньцзинь, Китай
}

\begin{abstract}
Выполнено численное моделирование с помощью вычислительного пакета ABAQUS ударного взаимодействия митени толщиной 1 мм из алюминиевого сплава 2 A12 со снарядом из высокопрочной стали $38 \mathrm{CrSi}$ с затупленной носовой частью при малых углах атаки. После экспериментальной проверки эффективности разработанных моделей проанализировань типь разрушения и роста трещцин в мишени с учетом последующего движения и изменения угла атаки снаряда. Результаты численных расчетов свидетельствуют о многостадийном характере деформирования и разрушения мишени при соударении и обнаружении трех типичных конфигураций "пробок”, пробиваемых снарядом в мишени. Установлена начальная скорость снаряда, при которой наблюдается изменение характера трещинообразования и роста трещин в митени. Рассчитано изменение траектории снаряда после соударения с увеличением угла атаки и отклонением от прямолинейной траектории, что может быть связано с действием радиальной силь при контакте снаряда с мишенью. Показано, что основными факторами, контролирующими движение снаряда после соударения, являются начальный угол атаки и скорость снаряда.
\end{abstract}

Ключевые слова: угол атаки, мода разрушения, траектория движения, варьирование угла атаки.

Introduction. Many factors are involved in plate perforation problem, such as material strength [1, 2], thickness of target [3, 4], figure of projectile [5-7], and number of layers [8], et al. Among these factors, the initial orientation of the projectile before impact cannot be neglected for the resistance performance and target failure mode assessment. Since an asymmetrical force would be generated between projectile and target due to the obliquity angle and yaw angle, this force will have a strong influence on the motion of projectile and failure mode of target, which could make the solution quite complicated. However, no unified theory that can accurately describe and solve the problem of impacting has been established yet.

Some beneficial investigations of the yaw angle impact have been reported, including experimental, theoretical, and numerical ones. Goldsmith $[9,10]$ summarized a series of experiments under various yaw angles to study the penetration and perforation response of thin metallic plates. He concluded that the yaw angle of projectile affected the deformation of target and it was reasonable to regard the impact progress as a normal impacting if the yaw angle of projectile was no more than $5^{\circ}$, while higher angles would cause a 
distinguishing difference. Moreover, the ballistic limit based on the theoretical results was somewhat lower than the experimental ones, a better correlation being found at high yaw angles.

Borvik et al. [11] conducted the experiment on a blunt-nosed projectile impacting Weldox $460 \mathrm{E}$ steel target: from the pictures captured by camera they found that, due to the aerodynamic force instability, it was very difficult for the projectile to keep absolutely perpendicular to target during its flight, thus the yawing impact become universal in many experiments. Fortunately, most experiments can be considered an ideal normal impact if the yaw angle is small enough.

Sikhanda et al. [12] analyzed the transient behavior of a yawed long rod projectile penetrating an oblique thin plate by applying the Laplace transformation and numerical inversion. They found that the length and gyration radius of projectile had a significant influence on the shear and moment distribution of target both in theoretical model and simulation results, moreover, the behavior of square and circular projectile was roughly similar.

Li and Flores-Johnson [13] presented a general framework of rigid projectile penetration and studied the projectile trajectory in the soil medium under various oblique and yaw angles by ABAQUS code. The numerical result showed that the location of mass center of projectile had a strong influence on the projectile stability and trajectory direction under certain initial oblique and yaw angles.

Although the failure mode of target and performance of projectile are key issues in the studies of yawing impact, most investigations disregarded the target and projectile interaction. To investigate the detailed mechanisms, a series of numerical models for slightly yawed hard $38 \mathrm{CrSi}$ steel projectiles $\left(1,3,5,7\right.$, and $10^{\circ}$ ) impacting thin $2 \mathrm{~A} 12$ aluminum target are presented in this paper. In Section 2, the model effectiveness is validated by the impacting experiment of double targets with a gap. Then the failure mode of target and the performance of projectile is analyzed in Section 3 to study the relations between target and projectile.

1. Simulation Model. A blunt-nosed cylindrical projectile with $12.62 \mathrm{~mm}$ diameter and $37.8 \mathrm{~mm}$ length (denoted as $D$ and $L$ separately) is used, and some volume in tail is hollowed out to make the centroid forward, this geometry of projectile comes from [14]. The target shape is a circular plate with $200 \mathrm{~mm}$ diameter and $1 \mathrm{~mm}$ thickness. Figure 1 shows the initial attitude of projectile and target before impacting. The direction extended from the target center to periphery is defined as radial in this model, and the direction along the target thickness is defined as transverse, while the counterclockwise direction is regarded as positive. The point $G$ in Fig. 1 is the centroid of projectile and its initial position is located at the central axis of target, $L_{G}$ is the distance between point $G$ and the nose of projectile, which equals to $16.82 \mathrm{~mm}$. Parameter $\alpha$ represents the obliquity of projectile (the angle between velocity vector of projectile and central axis of target), $\beta$ is the trajectory angle of projectile, which is the angle between the central axis of projectile and target. Value of $\theta$ is the yaw angle of projectile that is defined by the angle between the projectile central axis and its velocity vector [10]. Since the main purpose of this study is to examine the yaw angle effect on the failure mode of the target, the trajectory angle and oblique angle are taken as observations but not the independent variables, so the initial angle of projectile is

$$
\left.\alpha\right|_{t=0}=0,\left.\quad \theta\right|_{t=0}=\left.\alpha\right|_{t=0}+\left.\beta\right|_{t=0}=\beta_{0} .
$$

The explicit finite element software ABAQUS/Explicit-6.10 is used to establish the numerical model and analyze the dynamical behavior. The target material is 2A14-T4 aluminum alloy, while a slightly modified Johnson-Cook constitutive relation and corresponding failure criterion [15] are used to describe the target behavior, whereas the 


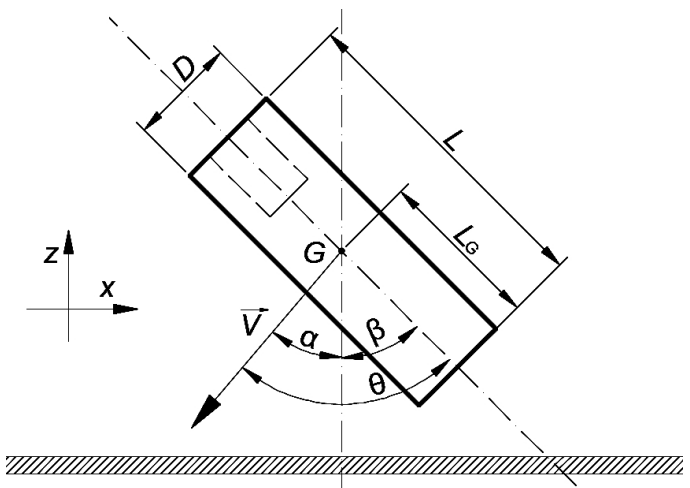

Fig. 1. The projectile and target orientations.

model constants are taken from [15]. The experiment shows that deformation in impacting of the projectile made of strengthened $38 \mathrm{CrSi}$ steel is negligible [16], so the bilinear hardening model is selected to describe the projectile behavior, and the required constants are taken from [17]. The constitutive relation and failure criterion for the material under study was implemented via the user subroutine VUMAT coded in Fortran, which is described in detail elsewhere [18]. The target boundary being restrained with respect to all degrees of freedom (which means that it does not move during impacting), eight-node brick elements (C3D8R) are considered in all simulations carried out in the present study.

The projectile is subdivided into uniform grids, whose size is $1 \times 1 \times 1 \mathrm{~mm}$, while a a transitional division strategy is adopted for the target. Elements in the central region with radius of $15 \mathrm{~mm}$ are dense $(0.2 \times 0.2 \times 0.2 \mathrm{~mm})$ due to a significant plastic deformation. The grid subdivision becomes more and more sparse from the central region to its boundary. The total number of grids is 5328 for the projectile and 177,220 for the target. Figure 2 shows the assembly of projectile and target before impacting. The erosion algorithm is adopted by which the element is deleted when the plastic strain is increased up to 5 times, in case the calculation is terminated for excessive distortion. Since the experiments conducted in [5] indicated that the friction effect was negligible when the projectile was blunt-nosed, a zero friction coefficient between projectile and target is set, thus the friction effect is not considered in this paper.

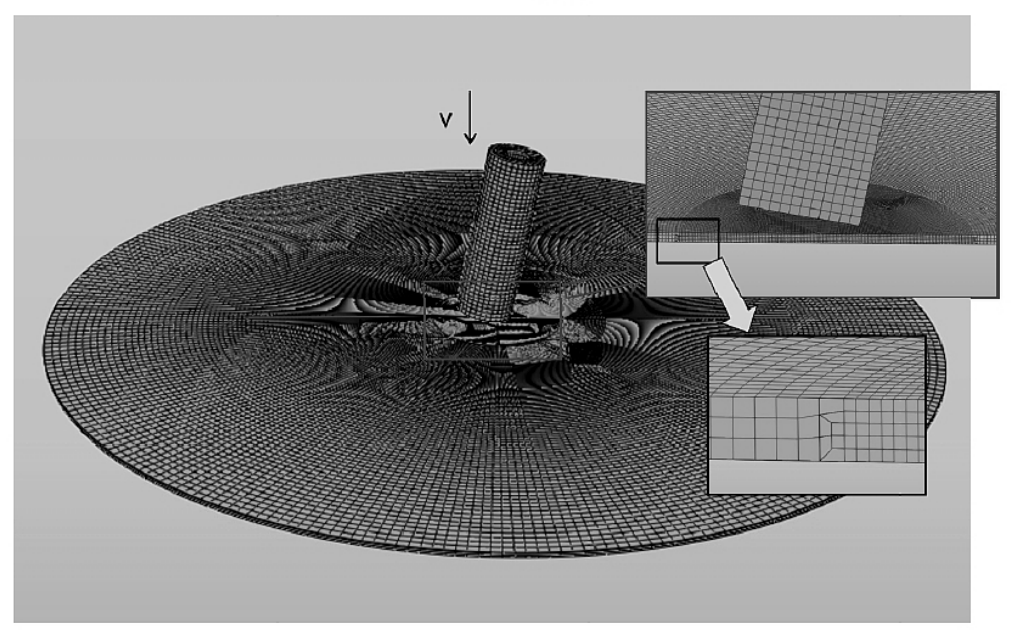

Fig. 2. Assembly of projectile and target. 
2. Verification. It is difficult to make the posture of projectile keep vertical during impacting in a true situation [11], and the objective boundary effect of target would result in some variation of the oblique angle of projectile [19], so it is appropriate to verify the effectiveness of the simulation model on the impact test where double targets with a gap are impacted by a blunt-nosed projectile launched by the gas gun.

Figure 3 illustrates the impact test scheme, in which the gap between the double targets is $100 \mathrm{~mm}$. Since the impacted point of first target is not coincident with its center, this deviation contributes a minor angular velocity to projectile after the first target is penetrated, then this angular velocity would make the projectile impact the second target with a small yaw angle, which means that the model effectiveness can be verified by comparing the simulation results for the second target, including the impact process and deformation.

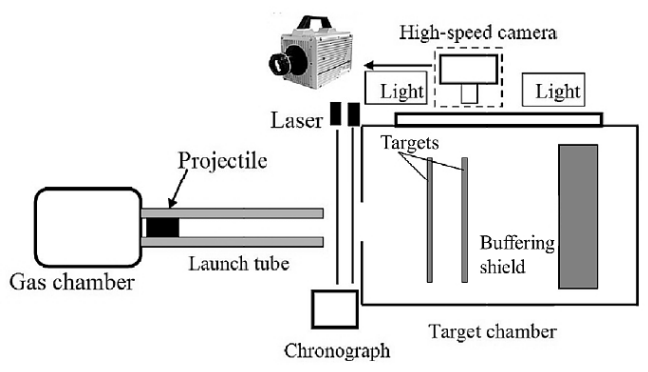

a

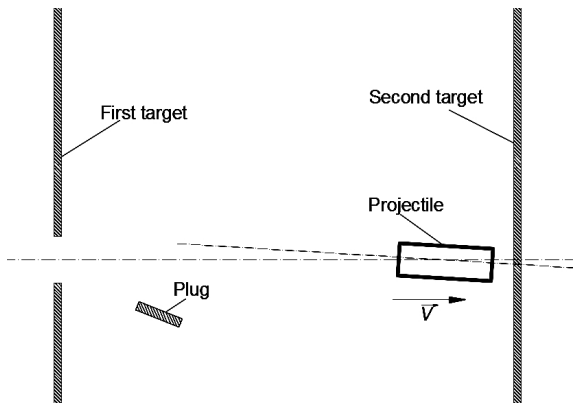

b

Fig. 3. Experiment of projectile impacting the double targets with a gap: (a) scheme of a single-stage gas gun system; (b) motion of projectile between the first and second targets.

The process of blunt-nosed projectile impacting the second target is depicted in Fig. 4, from which one can see that the projectile has a very small yaw angle (which cannot be neglected) before impacting and the motion trajectory is vertical to the target. However, there are some specific features and differences during penetration: on the one hand, the yaw angle of projectile exhibits an obvious increase, while, on the other hand, a plug of the target moves to one side. This behavior caused by the yawing projectile is consistent with the simulation model, so it is suitable to analyze the impact process by the numerical simulation.

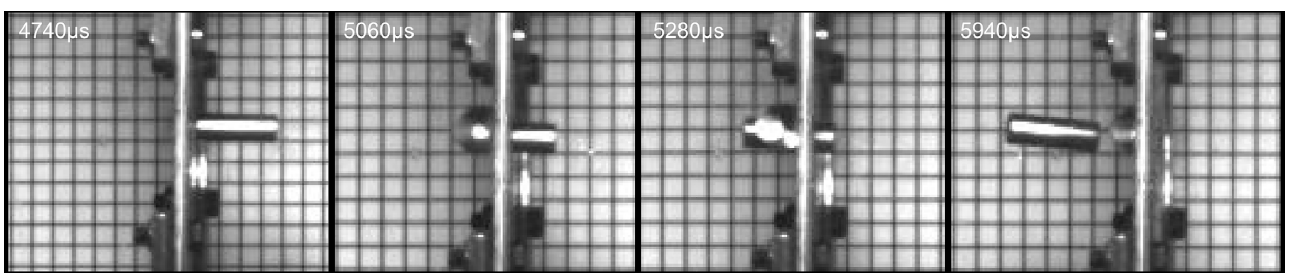

a

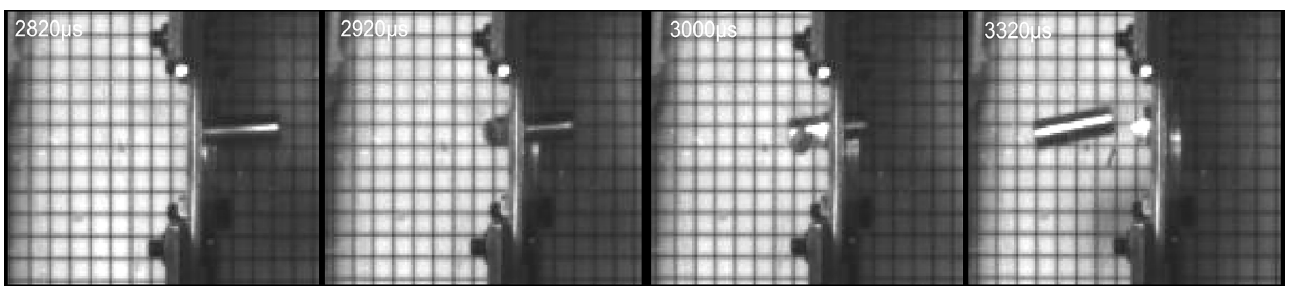

b

Fig. 4. Process of projectile impacting the second target: (a) $v_{0}=71.92 \mathrm{~m} / \mathrm{s} ;$ (b) $v_{0}=137 \mathrm{~m} / \mathrm{s}$. 
The numerically calculated target deformations for the initial yaw angles of 3 and $5^{\circ}$ are compared with the experimental ones, in order to analyze the effectiveness of the simulation model (see Fig. 5). The comparison shows that the numerical results exhibit a good fit with the experimental ones. Comparing the results depicted in Figs. 4 and 5, it is possible to draw the conclusion that the simulation model presented in this paper is valid and the simulation results are suitable to describe the true small-yawing impact.

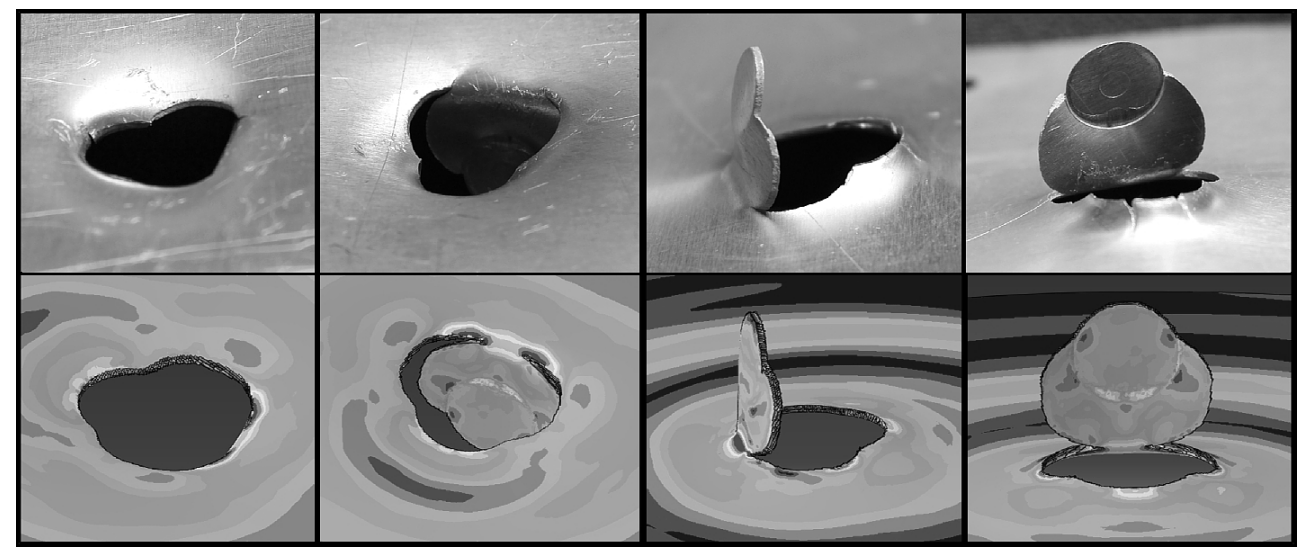

a

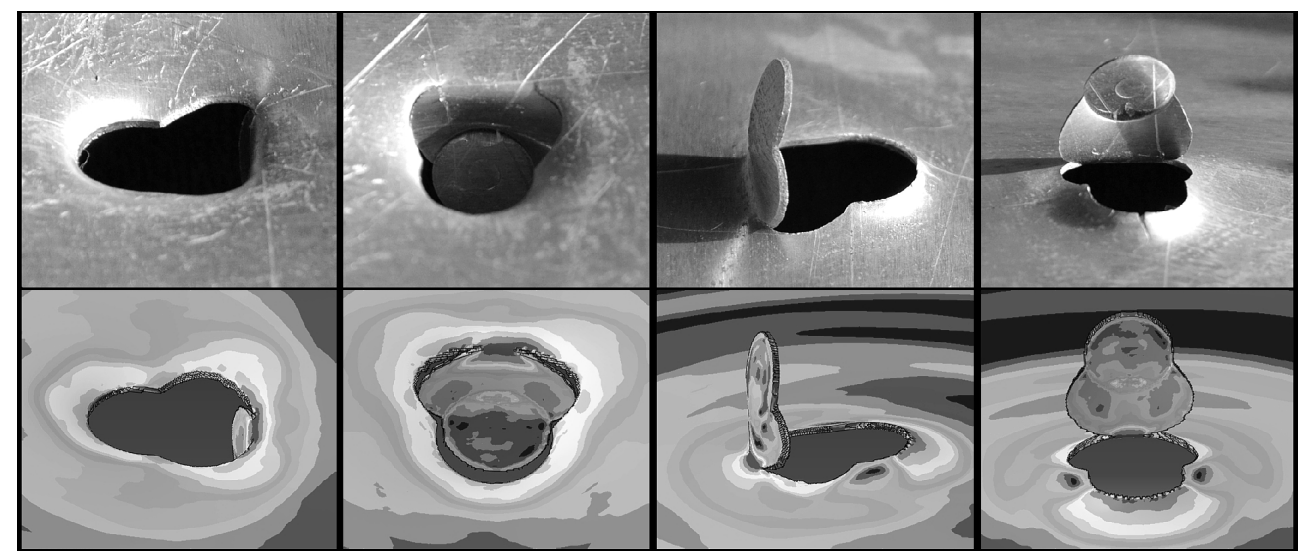

b

Fig. 5. Comparison between the experimental and numerical results: (a) $\theta_{0}=3^{\circ}, v_{0}=70 \mathrm{~m} / \mathrm{s}$; (b) $\theta_{0}=5^{\circ}, v_{0}=132.42 \mathrm{~m} / \mathrm{s}$.

\section{Analysis of Numerical Results.}

3.1. Failure Mode of Target. Comparison of the impact processes at different yaw angles shows that the yaw angle of projectile has a significant influence on failure mode of the target. When the initial velocity is within a certain range (higher than the ballistic limit and below a special point of velocity, the total perforation process can be subdivided into four stages according to the deformation of target shown in Fig. 6: (1) the initial contact with projectile and subsequent global deformation without crack; (2) the initial crack occurs and extends from the first contact area, in which stage the cracks propagate along the periphery of projectile; (3) cracks start to propagate along a new path at a certain point but not the periphery of projectilem while the plug moves to one side; (4) plug no longer touches the projectile due to its bending motion, furthermore, the bending of plug makes 
Numerical Study of Failure Modes and Crack Propagation ...

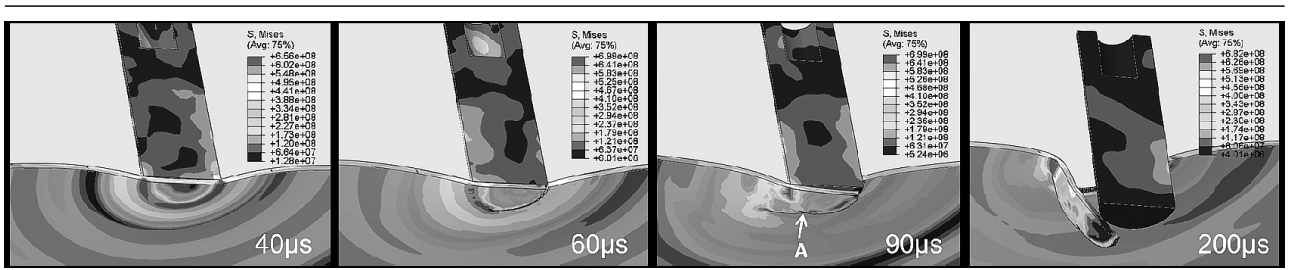

a

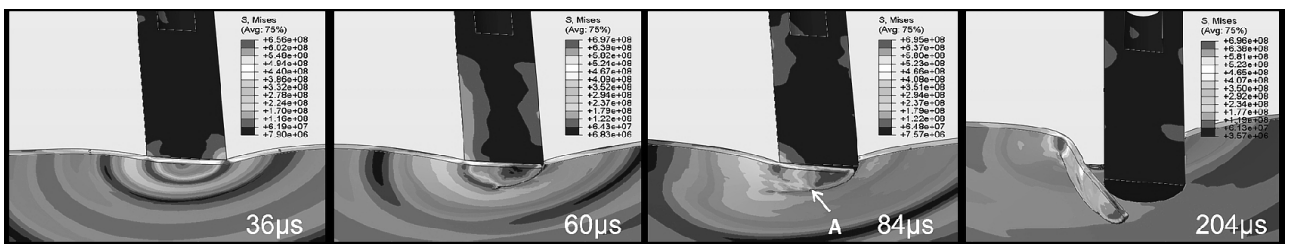

$\mathrm{b}$

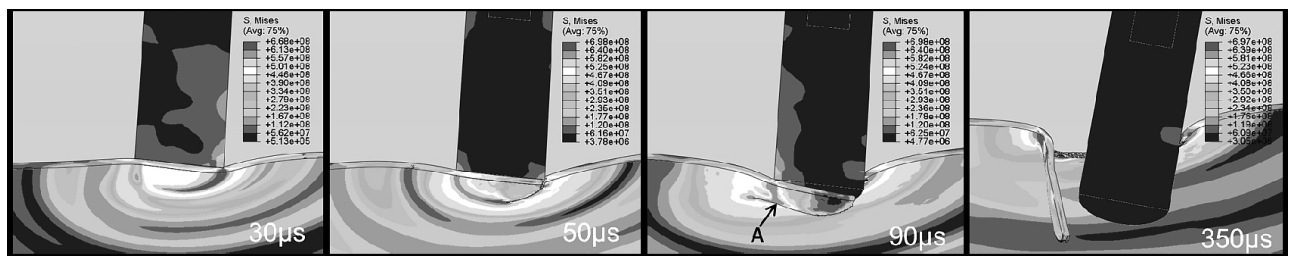

$\mathrm{c}$

Fig. 6. The impacting figures of projectile and target: (a) $\theta_{0}=3^{\circ}, v_{0}=96 \mathrm{~m} / \mathrm{s}$; (b) $\theta_{0}=5^{\circ}$, $v_{0}=93.13 \mathrm{~m} / \mathrm{s} ;$ (c) $\theta_{0}=10^{\circ}, v_{0}=100.5 \mathrm{~m} / \mathrm{s}$..

the cracks on both sides move together, while the projectile starts to have contact with the other side of fracture region of target and makes it appear like a local deformation.

Figure 7 shows some typical plug shapes after penetration. It is easy to find that the outline of plug consist of three parts. Part 1 occurs at Stage 2 as mentioned previously, in which stage the stress at the first contact area with projectile is the highest, with the continuous motion of projectile, the stress in the initial contact area excesses the ultimate tensile strength so that crack 1 appears, then it propagates along the projectile periphery because the stress value in this path is the highest, thus Part 1 is formed. Part 2 occurs at Stage 3 while the contact zone between target and projectile exhibits some change and plug starts to bend, which causes the displacement of the force application, when a crack propagates to a certain extent, whereas the transverse force and bending moment from the projectile would make the crack turn to another path at cracking point $A$ with an initial angle [20] but not the periphery of projectile. As shown in Fig. 6, this break process is similar to shredding mode of a light metal under the external force [21]. However, the complex interaction between the target and projectile implies that the crack propagation direction in the target crack varies under different conditions. The statistical results suggest that cracks at this stage mostly propagate along the outward arc, partly along tangent of the plug formed at Stage 2 or follow the combination of outward arc and tangent, which is more common for $\theta_{0}=10^{\circ}$. The detailed shapes of the above three cracks are shown in Fig. $7 \mathrm{a}, 7 \mathrm{~b}$, and 7c, respectively. Part 3 occurs at Stage 4, while the plug no longer touches the projectile, and the kinetic energy of the projectile decreases continuously, while the plug bending and the increasing radial tensile stress in the target back result in the crack propagation from both sides turning to the plug end and the final coalescence, causing plug disconnection from target and its motion with the remaining kinetic energy. 


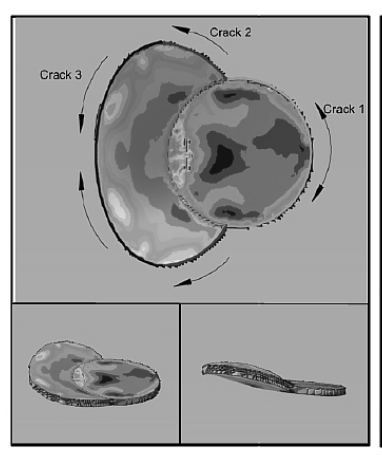

a

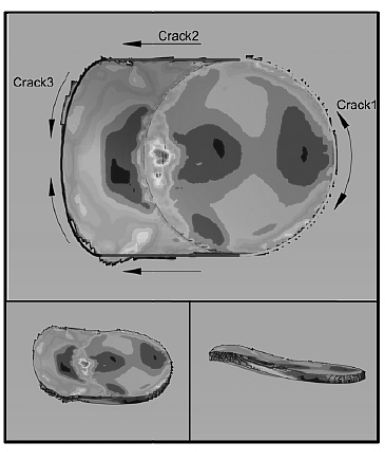

b

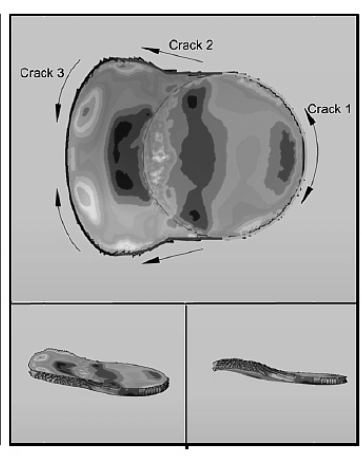

C

Fig. 7. Some typical figures of plugs: (a) $\theta_{0}=3^{\circ}, v_{0}=93.13 \mathrm{~m} / \mathrm{s}$; (b) $\theta_{0}=5^{\circ}, v_{0}=89.31 \mathrm{~m} / \mathrm{s}$; (c) $\theta_{0}=7^{\circ}, v_{0}=100.5 \mathrm{~m} / \mathrm{s}$.

In addition to the initial yaw angle that would influence the failure mode and plug shape of target, the initial velocity of projectile is an important factor that would produce the transformation of failure mode of target as well. Figure 8 shows the shape of plug penetrated by the projectile at different initial velocities. When the initial velocity exceeds the ballistic limit (but not much), the target would undergo the above-mentioned four stages of deformation and failure and produce the typical plug shapes as shown in Fig. 7. When the initial velocity of projectile attains a certain value, the stress difference at the whole boundary of target that directly contacts the projectile remains quite high due to the intensive impact load, thus the crack of Part 1 continues to expand along the periphery of projectile (marked as crack $1^{\prime}$ in Fig. 8) while the crack of Part 2 is expanding. If the initial velocity continues to increase, the cracks on the both sides of Part 1 of plug would converge in transverse directiuon and cut the plug into two parts, one of which is circular and leaves the target with the advance of projectile, while another part is still connected to the target and starts to contact with the body of projectile, while the crack of Part 2 stops expanding soon due to a sharp loss of kinetic energy obtained from the projectile. If the initial velocity is high enough, the cracks of Part 1 would join together even before the cracks of Part 2 occur. In this case, the original Stage 3 would disappear and the whole impact process would be similar to the process of blunt-nosed projectile impacting a thin metal target in the normal direction $[14,22]$, whereas one side of the target would exhibit a higher deformation due to the initial yaw angle.

The initial velocity controls the transformation of failure mode of the target, and the extent of such transformation is influenced by the initial yaw angle of projectile. The break velocity $v_{b}$, which is defined as the minimum initial velocity required to cut the plug into two parts, is adopted to depict the interrelation between the initial yaw angle and the transformation. Figure 9 illustrates that the break velocity increases with the initial velocity of projectile, which may be because the dominant force producing the crack of Part 1 of plug (marked as cracks 1 and $l^{\prime}$ in Fig. 8) is the vertical impact load coming from the projectile,which is related to the initial yaw angle of projectile.

As shown in Fig. 10, the velocity vector of projectile at the Stage 3 of impacting process can be represented in the local coordinate system $x^{\prime} 0 z^{\prime}$ by two orthogonal components $v_{x^{\prime}}$ and $v_{z^{\prime}} \cdot v_{x^{\prime}}$, which result in the continuous contact between the projectile body and one side of the fracture region, while $v_{z^{\prime}}$ mainly leads to the plug bending and further crack expansion. According to the function of target response presented by $\mathrm{He}$ [23], which is based on the simplified energy model proposed in [24-26], the stress in the plug at this stage is given by

$$
\sigma=A+B v_{z^{\prime}}+C v_{z^{\prime}}^{2}
$$




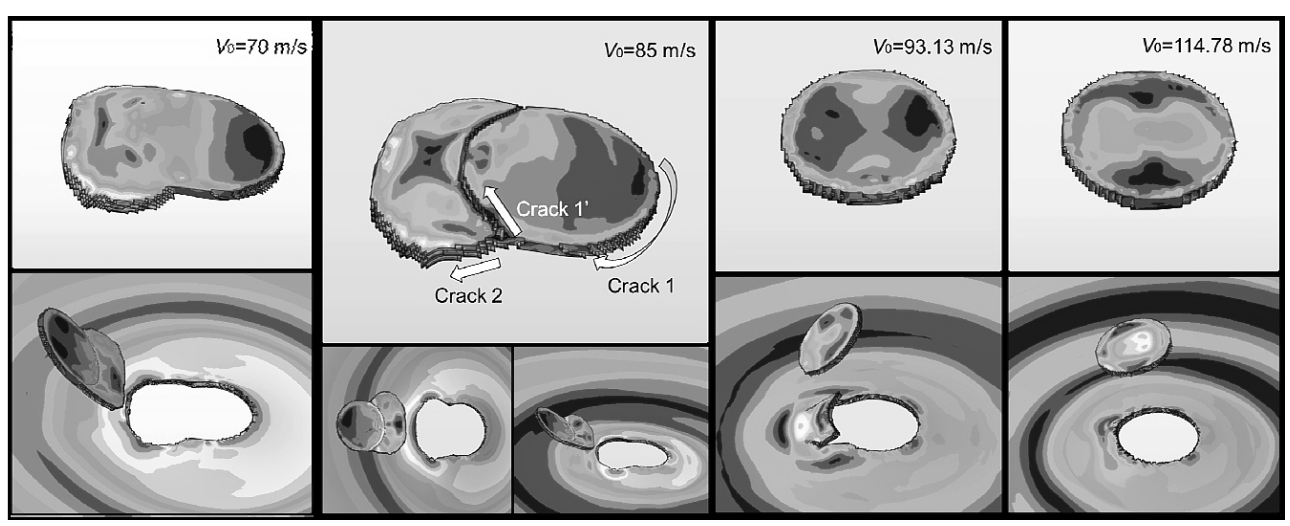

a

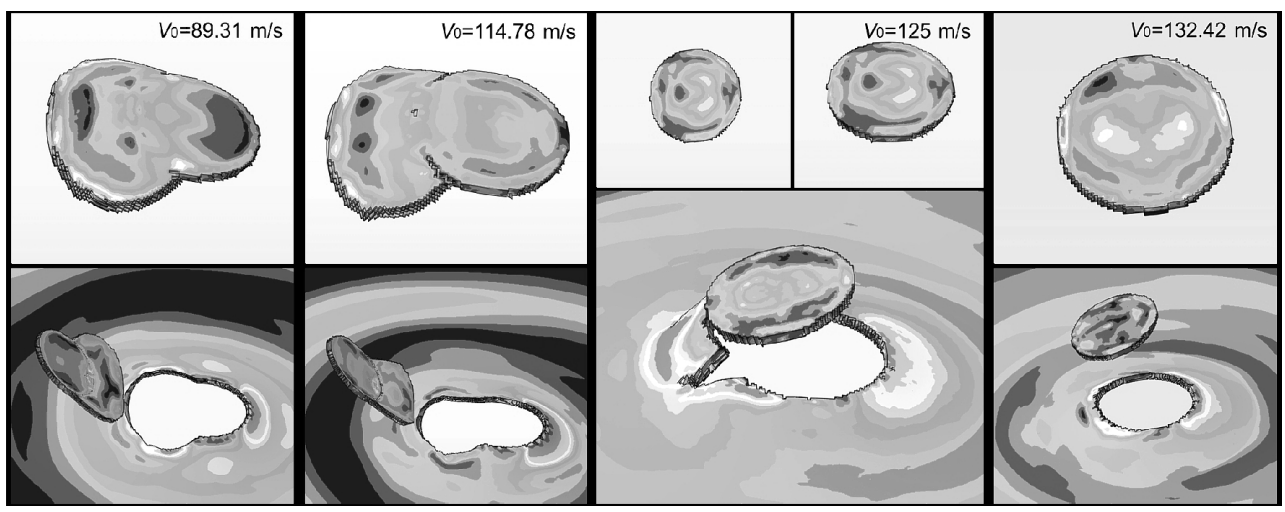

b

Fig. 8. Target failure modes for different initial velocities of projectile: (a) $\theta_{0}=1^{\circ}$; (b) $\theta_{0}=3^{\circ}$.

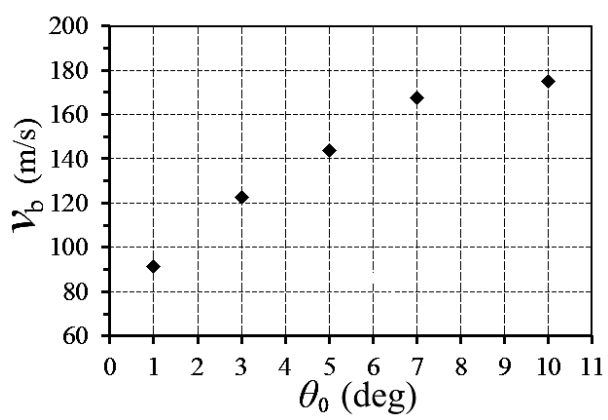

Fig. 9. The break velocity of plug at different yaw angles.

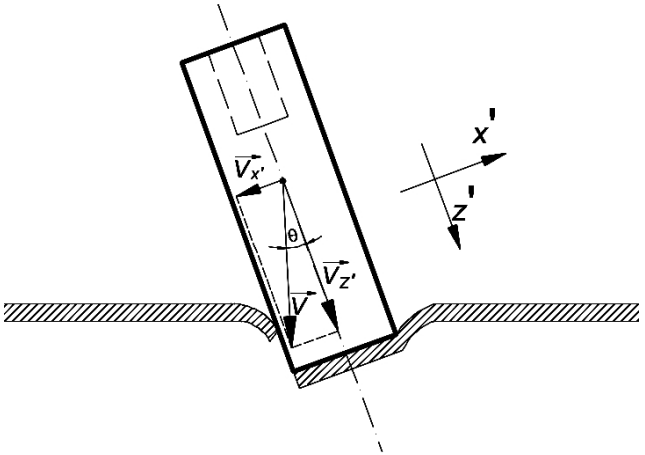

Fig. 10. Stage 3 of target and projectile impacting.

where $A, B$, and $C$ are undetermined constants. Assuming that crack $l^{\prime}$ on both sides of plug join together and cut the plug into two parts when the shear stress in the plug reaches the critical value $\tau_{c}$, then the function under critical condition is

$$
\pi D^{2} \sigma / 4=l_{c 1} H \tau_{c}=k D \pi H \tau_{c}
$$


where $l_{c 1}$ is the total length of crack $l^{\prime}$ on both sides of the plug, $k$ is the ratio of $l_{c 1}$ and circumference of the projectile nose, and $H$ is the target thickness. The statistical analysis of plug shapes at various initial yaw angles indicates that the parameter $k$ has no evident relation with the initial yaw angle, most of the values being between 0.45 and 0.55 , so it is reasonable to consider $k$ as constant.

The velocity component $v_{z^{\prime}}$ in Fig. 10 can be expressed as

$$
v_{z^{\prime}}=v \cos \theta
$$

As it was mentioned previously, the initial velocity of projectile must be high enough to cut the plug apart. Under this condition, the plug separates from the target at Stage 2 of the impacting process. According to a similar description presented in [10]), this duration is so short $(<20 \mu \mathrm{s})$ and the variation of the projectile behavior is so slight that $\theta$ and $v$ can be approximated as

$$
\theta=\theta_{0}, \quad v=v_{1},
$$

where $v_{1}$ is the projectile velocity before the plug splitting. The work-energy equation provides the velocity $v_{1}$ at the end of Stage 1 as

$$
\frac{m_{p} v_{0}^{2}}{2}-\frac{m_{p} v_{1}^{2}}{2}=E_{0}
$$

where $m_{p}$ is the mass of projectile and $E_{0}$ is the total energy absorbed by the target before its break. Based on Eqs. (2)-(6), the explicit relationship between $v_{b}$ and $\theta_{0}$ under the critical condition is given by

$$
\frac{4 k H \tau_{c}}{D}=A+B\left(v_{b}^{2}-\frac{2 E_{0}}{m_{p}}\right)^{1 / 2} \cos \theta_{0}+C\left(v_{b}^{2}-\frac{2 E_{0}}{m_{p}}\right) \cos ^{2} \theta_{0} .
$$

All parameters in Eq. (7) except $v_{b}$ and $\theta_{0}$ are undetermined constants, so it is easy to get the qualitative conclusion that if the initial yaw angle keeps increasing $\left(<90^{\circ}\right)$, then the initial velocity has to increase accordingly, in order to keep the balance of Eq. (7), which conclusion agrees well with the trend depicted in Fig. 9.

\subsection{Performance of Projectile.}

3.2.1. Trajectory of Centroid. During the impacting process, the interaction force has a significant influence on the performance of projectile as well, which can be demonstrated by the change of centroid position and angle variation of the projectile. Figure 11 shows the trajectories of some projectile centroids at various initial yaw angles, from which a significant influence of yaw angle on the trajectory of projectile is observed. For example, at the initial velocity of $70 \mathrm{~m} / \mathrm{s}$, the radial displacements of projectiles after penetration are $2,4.88,5.3,6.13$, and $8.14 \mathrm{~mm}$ for the initial angles of $1,3,5,7$, and $10^{\circ}$, respectively. A similar increase in the radial displacement is observed at other initial velocities, which means that a larger initial yaw angle of the projectile causes a higher deviation from its original trajectory. Furthermore, the initial velocity has the influence on the trajectory of projectile as well. As shown in Fig. 11, the radial displacement of projectile continually decreases with the initial velocity. A simple explanation of this phenomenon is that when the initial velocity becomes higher, the time required for the projectile to penetrate the target is respectively reduced, and the force acting on the projectile cannot create a high enough impulse for the projectile to get a high velocity, which makes the projectile trajectory quite close to the initial velocity direction. 


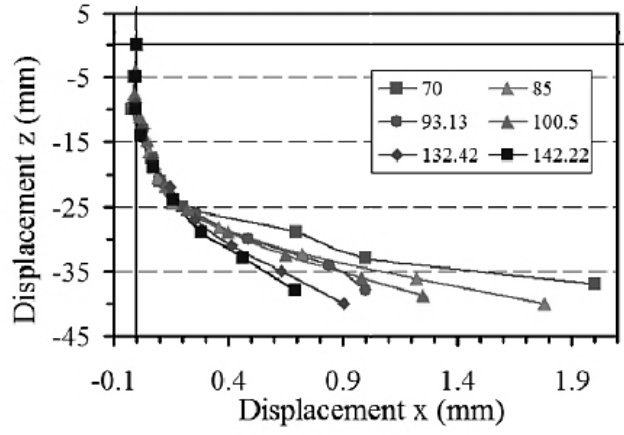

a

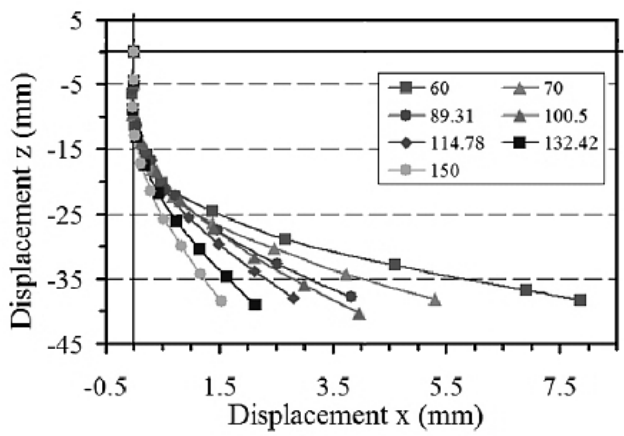

c

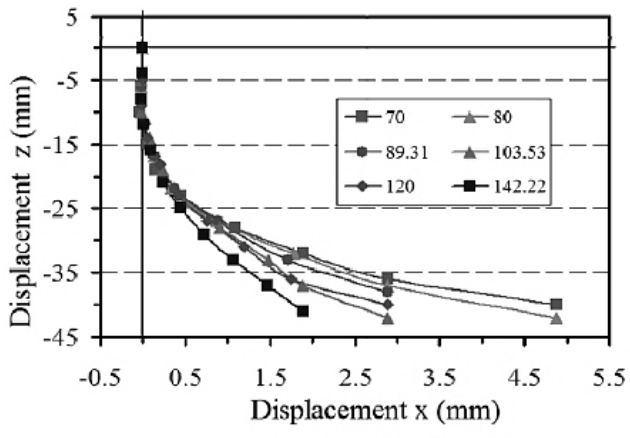

b

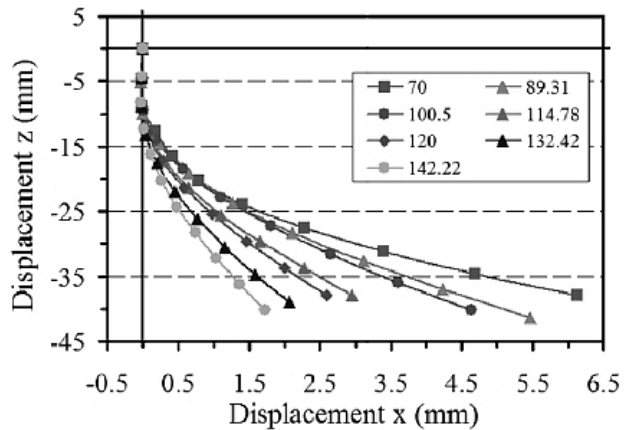

d

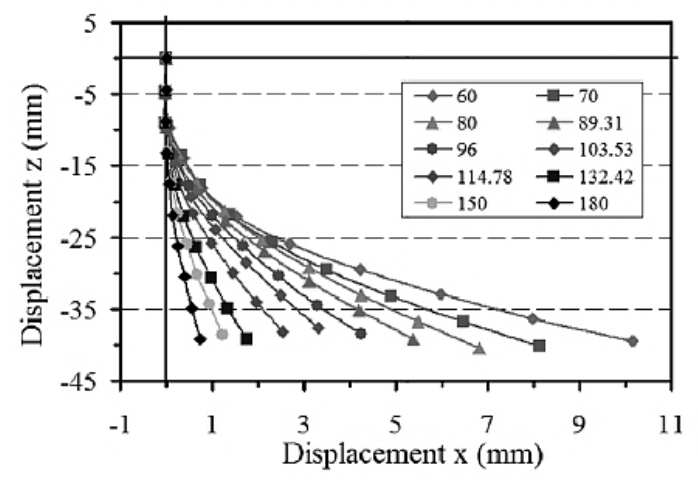

e

Fig. 11. The projectile centroid trajectory at various initial yaw angles: (a) $\theta_{0}=1^{\circ}$; (b) $\theta_{0}=3^{\circ}$; (c) $\theta_{0}=5^{\circ}$; (d) $\theta_{0}=7^{\circ}$; (e) $\theta_{0}=10^{\circ}$.

Figures 12 and 13 show the evolution of radial and transverse displacements of projectile at different initial yaw angles, respectively. The comparative analysis indicates that the transverse displacement linearly increases with time, while the radial one exhibit a strongly manifested quadratic curve shape; which suggests that the direction of force acting on the projectile changes at different impacting stages. The analysis of Figs. 12, 13, and 6 shows that during the first three impacting stages at small yaw angle the main direction of the force is transverse due to the interaction between the target and the projectile nose, while the total duration of these three stages is so short $(<100 \mu \mathrm{s})$ that a crack propagates and forms a plug very quickly. Considering that the initial direction of velocity before the 


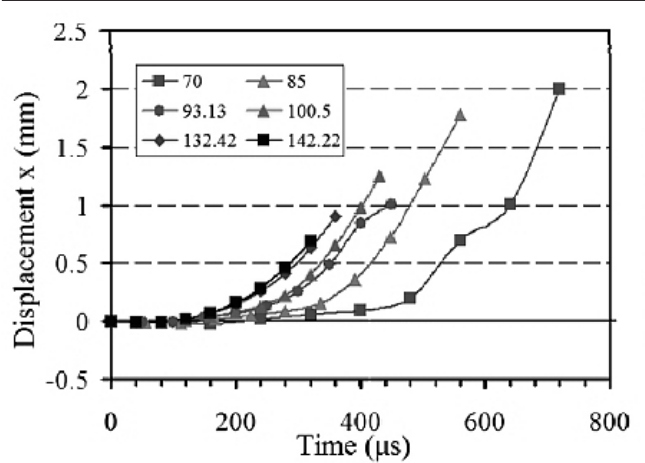

a

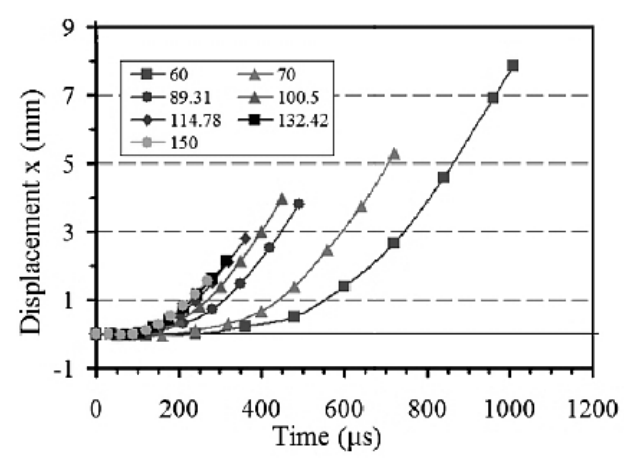

$\mathrm{c}$

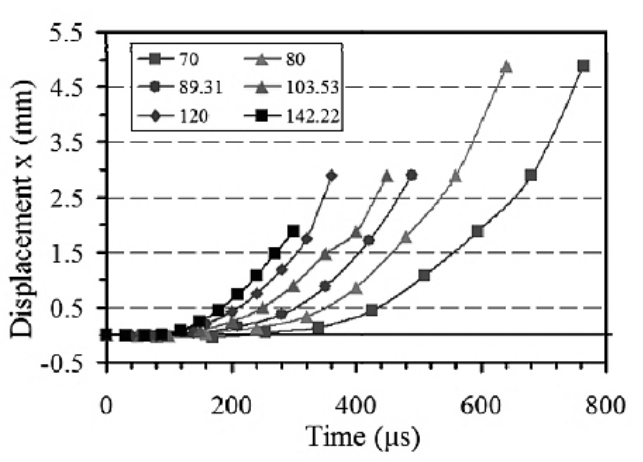

b

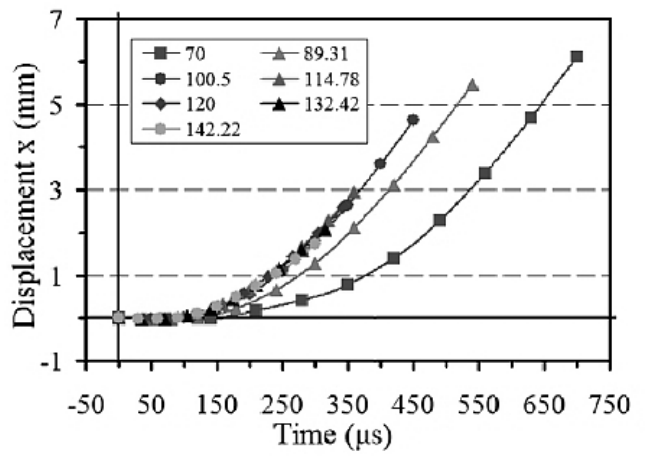

d

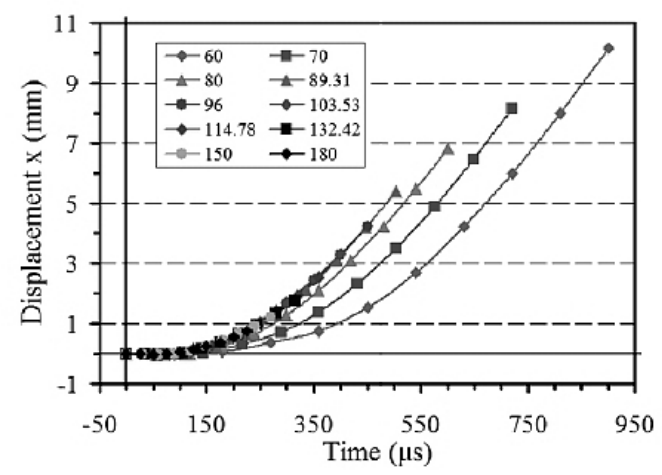

e

Fig. 12. Evolution of the projectile centroid radial displacements: (a) $\theta_{0}=1^{\circ}$; (b) $\theta_{0}=3^{\circ}$; (c) $\theta_{0}=5^{\circ}$; (d) $\theta_{0}=7^{\circ}$; (e) $\theta_{0}=10^{\circ}$.

impact is transverse, it is reasonable to assume that only a minor change of transverse velocity takes place at the first three stages, while the radial displacement increases slowly. Meanwhile, at Stage 4, which is a longer one, the plug separates from the projectile nose and the radial force between target and the body of projectile becomes the primary force. The effect of this radial force is to make the projectile move in the radial direction and rotate around its centroid. Thus a strongly manifested quadratic relationship between the radial displacement and time is observed at this stage, due to Newton's law of motion, while the transverse displacement vs. time exhibits a linear dependence because the projectile nose is no longer in contact with the target plug. 


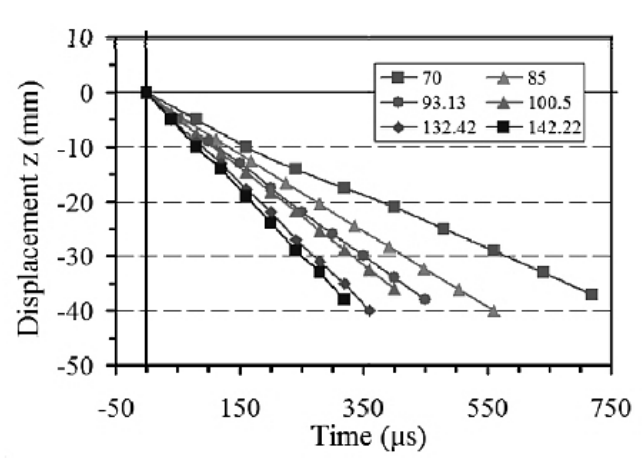

a

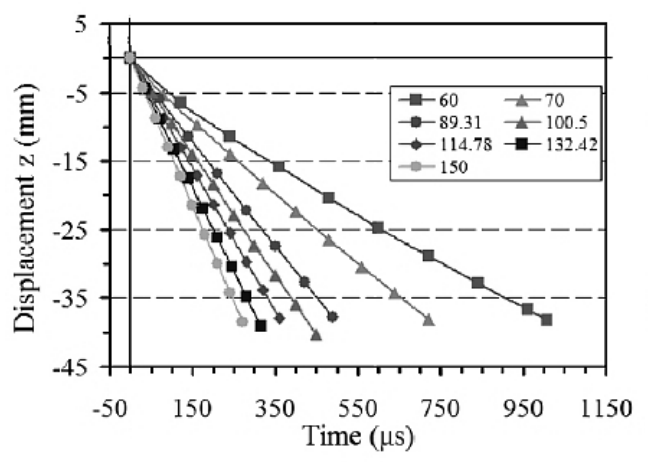

$\mathrm{c}$

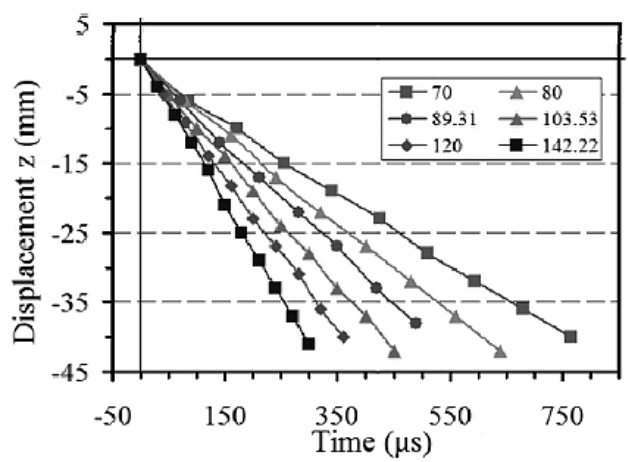

b

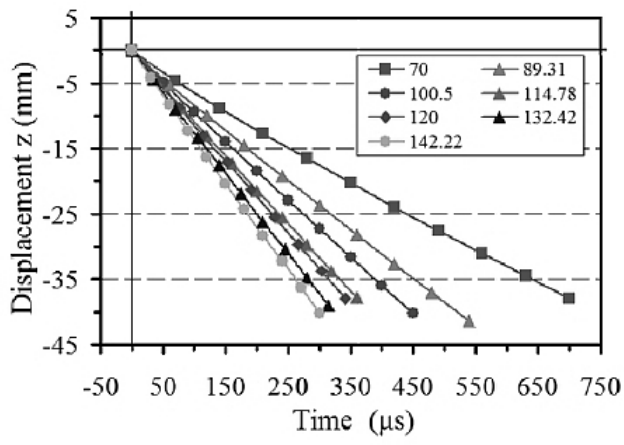

d

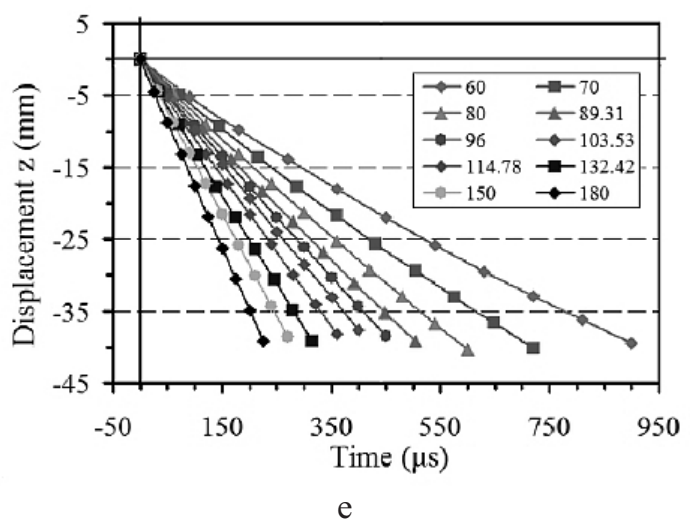

Fig. 13. Evolution of the projectile centroid transverse displacements: (a) $\theta_{0}=1^{\circ}$; (b) $\theta_{0}=3^{\circ}$; (c) $\theta_{0}=5^{\circ}$; (d) $\theta_{0}=7^{\circ}$; (e) $\theta_{0}=10^{\circ}$.

3.2.2. Trajectory Angle. Since the radial force which makes projectile move and rotate in the yawing impact process is objective, the trajectory angle, yaw angle, and obliquity angle exhibit some variation during impacting. Figure 14 shows the relationship between trajectory angle variation of some projectiles and time for the initial yaw angle values of 1 , 5 , and $10^{\circ}$, where the end of curve means that projectile has just penetrated the target at the corresponding time. It can be seen from Fig. 14 that both the initial yaw angle and initial velocity have influence on the trajectory angle. When the initial velocity is the same, the maximum value of trajectory angle increase with the initial yaw angle: in other words, a higher initial yaw angle results in the projectile's more apparent rotation around its centroid 


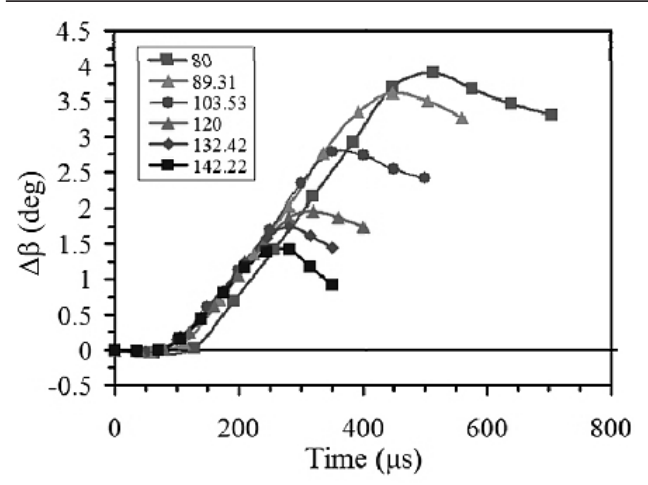

a

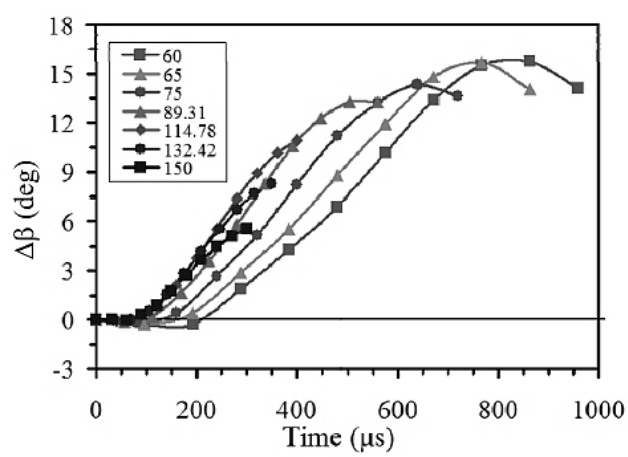

b

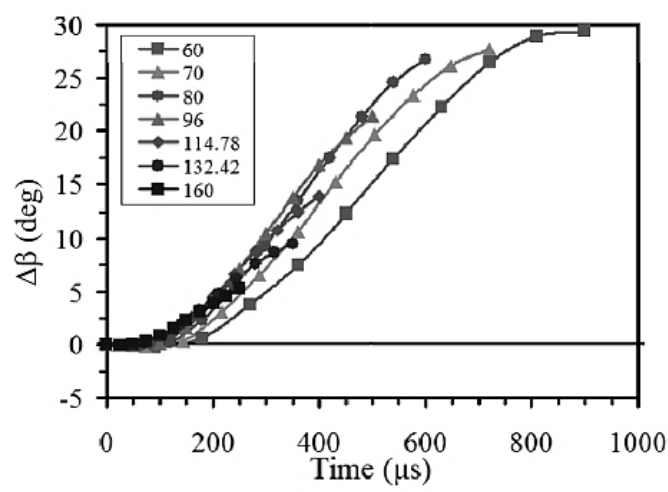

c

Fig. 14. Variation of the motion trajectory angle: (a) $\theta_{0}=1^{\circ}$; (b) $\theta_{0}=5^{\circ}$; (c) $\theta_{0}=10^{\circ}$.

during impacting. In addition to the yaw angle, Fig. 14a-c shows that the increase of initial velocity would reduce the trajectory angle variation of projectile, while the reduction of penetration time would shorten the curve, thus implying the backward trend. The analysis of Fig. 14 suggests that the projectile orientation after penetration is close to its original one if the initial yaw angle is low or the initial velocity is high, whereas in the opposite cases the orientation would exhibit a large variation.

More detailed plots in Fig. 14 show that the dependence between trajectory angle and time have periodic patterns but is not monotonic. Previous analysis reveals that the radial force on projectile at the first three stages is very low due to the short duration, which causes a negligible change of yaw angle, but at the longer Stage 4, it can be subdivided into two more detailed portions according to the force location between projectile and target (see Fig. 15a and b), which has different influence on the trajectory angle at the corresponding stage.

At Stage 4 of penetration at a small yawing angle, a plug ejects from the projectile and one side of the fracture zone contacts with the body of projectile, then the bending part of the target and the body of projectile are tangent-contacting based on the theoretical model presented by $\mathrm{Xu}$ et al. [27, 28], where the direction of force is vertical to the body of projectile with the effect of friction being disregarded. Assuming the centroid of projectile as origin of the moving local coordinate system $x^{\prime} 0 z^{\prime}$, the momentum moment theorem for the projectile is expressed as follows:

$$
J \frac{d \omega}{d t}=F s,
$$




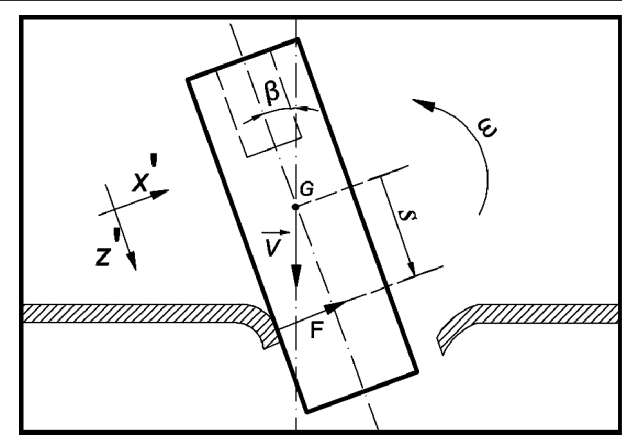

a

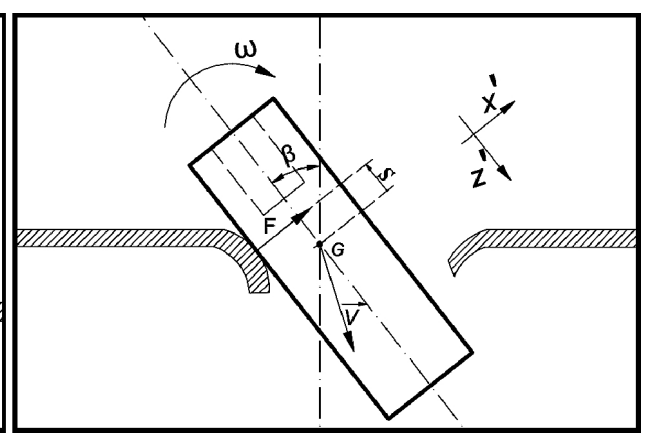

b

Fig. 15. Application scheme for the interaction force between projectile and target.

where $J$ is the moment of inertia of projectile around its centroid, $s$ is the lever arm from centroid $G$ to force $F$, and the differential relation of angle is given by

$$
d \alpha / d t=\omega .
$$

It can be seen from Eqs. (8) and (9) that parameter $s$ is positive when the projectile is moving as shown in Fig. 15a, which implies that the moment of projectile is positive and which leads to the increase of angular velocity as well as trajectory angle, during the impacting process. Here the angular velocity reaches its maximum when the action line passes through the centroid of projectile and then the projectile switches to another motion model as shown in Fig. 15b. According to this motion model, the values of parameter $s$ and moment are both negative, which results in the reduction of angular velocity and the slowdown of trajectory variation. If the angular velocity has not been reduced to zero after penetration, the projectile still has some positive angular velocity, while the trajectory angle keeps increasing. Vice versa, if the angular velocity has been reduced to zero before the projectile entirely penetrates the target, then the angular velocity would be negative and the curve of trajectory angle would start to descend from vertex, as shown in Fig. 14.

3.2.3. Obliquity Angle. Although the initial value is set to zero, the obliquity angle exhibits some change due to the interaction force between the projectile and target during impacting. Figure 16 shows the obliquity angle variation of projectiles after penetration at various initial yaw angles (since yaw angle has a direct mathematical relation with obliquity angle and trajectory angle, the detailed description of yaw angle during impacting is omitted for brevity). It is noteworthy that both the initial velocity and initial yaw angle have some influence on the obliquity angle. For the projectiles with the same initial yaw angle, a definitely negative correlation between the obliquity angle variation and the initial velocity is depicted in Fig. 16, which can be explained by acting time difference. During impacting the obliquity angle of projectile has a trigonometric relation with components of velocity on the $x$ and $z$ axes that is given by

$$
\tan \alpha=-v_{x} / v_{z} .
$$

A higher initial velocity means a higher transverse velocity and a shorter time to penetrate the target entirely, meanwhile the radial velocity obtained from radial force is low due to a shorter time, then the obliquity angle $\alpha$ is close to 0 according to Eq. (10).

Apart from the initial velocity, the initial yaw angle has some influence on the obliquity angle of projectile. As shown in Fig. 16, the difference between obliquity angles corresponding to various initial yaw angles is apparent. For projectiles with the initial yaw 


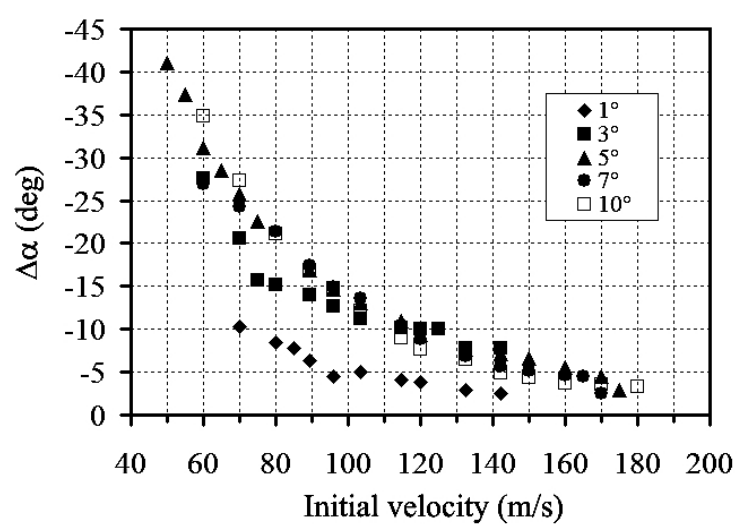

Fig. 16. The obliquity angle variation of projectiles with different initial velocity and yaw angle.

angle equal to $1^{\circ}$, the obliquity angle variation is slight, both at low or high initial velocities: the obliquity angle at low initial velocity is highest, then it drops rapidly with the increase in the initial velocity. The overall trend is an inverse function with the initial velocity in the range of 60 to $180 \mathrm{~m} / \mathrm{s}$. For the cases of 3, 5, and $7^{\circ}$ initial yaw angles, the obliquity angle variation appears more moderate as compared with the projectile at $1^{\circ}$ initial yaw angle. When the initial velocity is less than $100 \mathrm{~m} / \mathrm{s}$, the mutual relation between obliquity angle and initial yaw angle is positive, however, when the initial velocity exceeds $120 \mathrm{~m} / \mathrm{s}$, the obliquity angle variation with lower initial yaw angle begins to exceed those with higher initial yaw angles (except $1^{\circ}$ ). A possible explanation for this phenomenon is the break velocity $v_{b}$ : as seen from Fig. 8 , the size of fracture zone tends to decrease when the initial velocity exceeds $v_{b}$. The body of projectile starts to contact the total fracture zone instead of one side (as shown in Fig. 15), and this change makes the interaction between projectile and target more complex. It also causes a higher obliquity angle variation of projectile with a low initial yaw angle when the initial velocity is high. Unfortunately, there is no sufficient evidence to verify this assumption, which is envisaged in the future work.

Conclusions. A simulation model of a $2 \mathrm{~A} 12$ aluminum thin target against a blunt-nosed high-strength projectile at a small yaw angle was elaborated with the help of ABAQUS/Explicit finite element code, and its effectiveness was verified by predicting the target failure mode for different initial angles, as well as the performance of projectile. The following conclusions can be drawn:

1. For the failure mode of target, different features are observed during impacting: if the initial velocity of projectile is within a certain range, the impact process can be subdivided into four stages according to the deformation and the crack propagation patterns. Three typical shapes of target plugs are obtained after penetration, the major difference among plugs being the crack propagation at Stage 3.

2. There is a break velocity of projectile that can transform the target failure mode, above which the plug would be cut into two parts due to a high impact load. The mathematical derivation implies that the break velocity has a positive relationship with the initial yaw angle, which conclusion is corroborated by the general numerical results.

3. The interaction force between target and projectile also has an influence on the projectile, including its trajectory and angle variation. The detailed analysis reveals that higher yaw angles generate higher interaction forces and moments, due to which the projectile motion parameters undergo a more significant variation. Furthermore, if the initial velocity of projectile is low, then the necessary time to penetrate the target becomes longer, which also causes a more significant variation of the projectile motion parameters. 
Acknowledgments. A part of this work was financed by the Fundamental Research for the Central Universities (No. 3122014D018) and another part - by the National Natural Science Foundation of China (No. U1233107). The computational effort was supported by the College of Aeronautical Engineering at CAUC in China. Finally, we would like to acknowledge the helpful comments of the reviewers.

\section{Резгме}

Виконано числове моделювання за допомогою обчислювального пакета ABAQUS ударної взаємодії мішені товщиною 1 мм з алюмінієвого сплаву 2А12 зі снарядом із високоміцної сталі $38 \mathrm{CrSi}$, що має затуплену носову частину, за малих кутів атаки. Після експериментальної перевірки ефективності розроблених моделей проаналізовано типи руйнування та росту тріщин у мішені з урахуванням наступного руху і зміни кута атаки снаряда. Результати числових розрахунків свідчать про багатостадійний характер деформування і руйнування мішені при співударі та виявлення трьох типових конфігурацій “пробок”, які пробиваються снарядом у мішені. Установлено початкову швидкість снаряда, за якої змінюються характер тріщиноутворення і ріст тріщин у мішені. Розраховано зміну траєкторії снаряда після співудару зі збільшенням кута атаки і відхиленням від прямолінійної траєкторії, що може бути пов’язано з дією радіальної сили при контакті снаряда 3 мішенню. Показано, що основними чинниками, що контролюють рух снаряда після співудару, є початковий кут атаки і швидкість снаряда.

1. G. Wei, W. Zhang, W. Huang, et al., "Effect of strength and ductility on deformation and fracture of three kinds of aluminum alloys during Taylor tests," Int. J. Impact Eng., 73, 75-90 (2014).

2. P. Jannotti, G. Subhash, and A. K. Varshneya, "Impact-induced deformation mechanisms in unstrengthened and chemically strengthened glass bars," Int. J. Impact Eng., 75, 53-64 (2015).

3. B. Mishra, P. K. Jena, B. Ramakrishna, et al., "Effect of tempering temperature, plate thickness and presence of holes on ballistic impact behavior and ASB formation of a high strength steel," Int. J. Impact Eng., 44, 17-28 (2012).

4. L. H. Nguyen, S. Ryan, S. J. Cimpoeru, et al., "The effect of target thickness on the ballistic performance of ultra high molecular weight polyethylene composite," Int. J. Impact Eng., 75, 174-183 (2015).

5. T. Børvik, M. Langseth, O. S. Hopperstad, and K. A. Malo, "Perforation of $12 \mathrm{~mm}$ thick steel plates by $20 \mathrm{~mm}$ diameter projectiles with flat, hemispherical and conical noses: Part I: Experimental study," Int. J. Impact Eng., 27, 19-35 (2002).

6. T. Børvik, O. S. Hopperstad, T. Berstad, and M. Langseth, "Perforation of $12 \mathrm{~mm}$ thick steel plates by $20 \mathrm{~mm}$ diameter projectiles with flat, hemispherical and conical noses: Part II: Numerical simulations," Int. J. Impact Eng., 27, 37-64 (2002).

7. M. A. Iqbal, S. H. Khan, R. Ansari, and N. K. Gupta, "Experimental and numerical studies of double-nosed projectile impact on aluminum plates," Int. J. Impact Eng., 54, 232-245 (2013).

8. C. W. Ong, C. W. Boey, R. S. Hixson, and J. O. Sinibaldi, “Advanced layered personnel armor," Int. J. Impact Eng., 38, No. 5, 369-383 (2011).

9. W. Goldsmith, "Non-ideal projectile impact on targets," Int. J. Impact Eng., 22, Nos. 2-3, 95-395 (1999).

10. W. Goldsmith, E. Tam, and D. Tomer, "Yawing impact on thin plates by blunt projectiles," Int. J. Impact Eng., 16, No. 3, 479-498 (1995). 
11. T. Børvik, O. S. Hopperstad, M. Langseth, and K. A. Malo, "Effect of target thickness in blunt projectile penetration of Weldox $460 \mathrm{E}$ steel plates," Int. J. Impact Eng., 28, No. 4, 413-464 (2003).

12. S. Satapathy, A. Bedford, and S. Bless, "Behavior of a yawed projectile penetrating a thin plate," Int. J. Impact Eng., 21, No. 7, 597-608 (1998).

13. Q. M. Li and E. A. Flores-Johnson, "Hard projectile penetration and trajectory stability," Int. J. Impact Eng., 38, No. 10, 815-823 (2011).

14. Y. Deng, W. Zhang, and F. Meng, "Ballistic performance of Q235 metal plates subjected to impact by blunt-nosed projectiles," J. Harbin Inst. Technol., 47, No. 3, 54-59 (2015).

15. W. Zhang, G. Wei, and X. Xiao, "Constitutive relation and fracture criterion of $2 \mathrm{~A} 12$ aluminum alloy," Acta Armamentarii, 34, No. 3, 276-282 (2013).

16. Y. Deng, J. Li, and F. Meng, "Ballistic performance of Q235 metal plates subjected to impact by ogival-nosed projectiles," J. Mech. Eng., 51, No. 17, 66-71 (2015).

17. T. Børvik, O. S. Hopperstad, T. Berstad, and M. Langseth, "A computational model of viscoplasticity and ductile damage for impact and penetration," Eur. J. Mech. ASolid., 20, No. 5, 685-712 (2001).

18. Q. Wu, A Study on the Penetration Resistance of Targets Made of Various Materials, University of Science and Technology of China, Hefei (2012).

19. R. Villavicencio and C. Guedes Soares, "Numerical modelling of the boundary conditions on beams stuck transversely by a mass," Int. J. Impact Eng., 38, No. 5, 384-396 (2011).

20. C. Wang, Z. Zhu, and H. Liu, "Study on predicting crack initiation angle," J. Sichuan Univ. (Engineering Science Edition), 47, No. 2, 28-35 (2015).

21. J. Liu, B. Yang, Z. Li, et al., "Study on shredding modes of light metal scrap," J. Mech. Eng., 47, No. 12, 48-55 (2011).

22. I. Mohagheghian, G. J. McShane, and W. J. Stronge, "Impact perforation of monolithic polyethylene plates: Projectile nose shape dependence," Int. J. Impact Eng., 80, 162-176 (2015).

23. T. He, A Study on the Penetration of Projectiles into Targets Made of Various Materials, University of Science and Technology of China, Hefei (2007).

24. H. M. Wen, "Predicting the penetration and perforation of FRP laminates structure normally by projectiles with different nose shapes," Compos. Struct., 49, No. 3, 321-329 (2000).

25. H. M. Wen, "Penetration and perforation of thick FRP laminates," Compos. Sci. Technol., 61, No. 8, 1163-1172 (2001).

26. H. M. Wen, "Predicting the penetration and perforation of struck by projectiles at normal incidence," Mech. Struct. Mach., 30, No. 4, 543-577 (2002).

27. S. Xu, W. Wu, X. Li, et al., "Petal failure characteristics of a conical projectile penetrating a thin plate at high oblique angle," J. Shanghai Jiaotong Univ., 15, No. 4, 434-440 (2010).

28. S. Xu, W. Wu, X. Li, and T. Huang, "Theoretical analysis on residual velocity of conical projectile after penetrating thin plate at low oblique angle," J. Ballistics, 22, No. 3, 58-62 (2010). 